\title{
Response to requests for general practice out of hours: geographical analysis in north west England
}

\author{
J Munro, R Maheswaran, T Pearson
}

J Epidemiol Community Health 2003;57:673-674

T he organisation of out of hours general practice (GP) in the UK has changed rapidly in recent years as practice based rotas and deputising services have given way to GP cooperatives in many areas. ${ }^{1}$ At the same time, the proportion of patients contacting an out of hours service who receive telephone advice only, rather than a face to face consultation, has risen substantially, ${ }^{2}$ although patients continue to express strong preferences for personal contact with a doctor out of hours. ${ }^{3}$ We examined the effect of the distance of the patient from the primary care centre on the doctor's decision to see the patient face to face.

\section{METHODS AND RESULTS}

The setting for this study was a town of about 130000 in the north west of England, with an economy based on traditional manufacturing industries, commerce, and administration. Out of hours primary care services were provided by a single cooperative of 116 general practitioners operating from a primary care centre located in the town centre, serving a total population of 230000 patients in the town and surrounding suburban and rural areas. The cooperative received about 25000 calls per year, which were triaged by an on call general practitioner in the primary care centre to receive a home visit (from a second mobile on call doctor), to attend the primary care centre, or to receive telephone advice only.

All calls to the cooperative were routinely logged to a database. Data were obtained for all calls from 20 May 1997 to 30 July 1998 and for each, the date and time of the call, date of birth, sex, and postcode of the patient, and initial triage decision of the on call doctor were recorded. The postcode was used to derive the straight line distance and road travel distance (using 1 to 200000 resolution road network data) from the patient's home to the primary care centre, the 1991 census based Townsend score of the enumeration district of residence (as an indicator of socioeconomic deprivation) and the urban-rural classification of the electoral ward of residence (using the Office for National Statistics six category classification). The triage decision was recoded into two binary variables: whether or not the patient was to be seen in person and whether or not the patient was to be seen at home.

Two logistic regression analyses were undertaken. In the first, we examined the influence of distance from the primary care centre on whether or not the patient was to be seen in person, adjusting for the effects of age $(0,1-4$, then five year bands), sex, deprivation category (by quintile), rurality (categories 1-2,3-4,5-6), time of day (midnight to 8 am, 8 am to $6 \mathrm{pm}, 6 \mathrm{pm}$ to midnight), and day of week (weekday, weekend). In the second, selecting only calls in which the patient was to be seen, we examined the influence of distance on the decision to see the patient either at home or at the primary care centre, adjusting for the same set of factors. We used the Huber-White standard error estimation (cluster) adjustment within STATA to take into account calls made by the same person, * having defined individuals as those having the same date of birth, sex, and postcode. Altogether 4681 calls were excluded because of incomplete data or because they were classified as no charge (inappropriate) calls.

Of the 31048 calls analysed, 57\% (17 600 of 31048 ) were offered face to face consultation. Of these, $75 \%$ (13 187 of 17600 ) were to be seen at the primary care centre and $25 \%$ (4413 of 17600 ) at the patient's home. The likelihood of a patient being seen face to face fell progressively with increasing road travel distance to the primary care centre. However, given that the patient was to be seen at all, distance seemed to have little effect on whether they would be seen at home or at the centre (table 1). Analyses using straight line distances gave similar results.

With regard to the other variables in the model, the likelihood of seeing a doctor also fell with increasing deprivation, although if a patient was to be seen then those from more deprived areas were more likely to be seen at home than those from less deprived areas. Female patients were less likely to be seen in person than male patients. The rurality of the patient's area had no significant effect either on whether or where to see the patient. Patients calling overnight (between midnight and $8 \mathrm{am}$ ) were less likely to be seen in person than those calling at other times but, if they were to be seen, more likely to be seen at home. The likelihood of being seen face to face was higher for weekend than for weekday callers.

\section{COMMENT}

These results suggest that patients contacting out of hours primary care services may be less likely to see a doctor in person the further they live from the primary care centre. This is consistent with a similar finding reported in a study of a rural GP cooperative in Northern Ireland. ${ }^{4}$ In the case of many of the variables examined, it is possible that confounding by case severity may have occurred. For example, patients calling from more deprived areas or at particular times may have conditions of differing severity from those calling from other places or at other times, which call for a different response from the cooperative. The decreasing likelihood of being seen face to face with increasing distance from the centre could be the result of calls from further away being less severe, though this seems unlikely.

Recent proposals to change the organisation of out of hours care in the UK further, ${ }^{5}$ locating the responsibility for commissioning care with organisations such as Primary Care Trusts, which may have populations in excess of 100 000, seem to be moving towards services covering increasingly large populations. As these changes occur, careful thought will need to be given to how best to ensure geographical equity of access to medical care out of hours. The number of primary care centres or mobile doctors may have to be increased, or additional transport facilities provided for patients, to avoid disadvantaging those who live furthest from primary care centres.

*The Huber-White adjustment provides a robust estimate of standard error for clustered data without making distributional assumptions. 
Table 1 Odds ratios for decision to see the patient in person, and for those to be seen, on the decision to see the patient at home, in response to telephone requests for general practice out of hours

\begin{tabular}{|c|c|c|c|c|c|c|}
\hline & \multicolumn{3}{|c|}{ Decision to see patient } & \multicolumn{3}{|c|}{ Decision to see patient at home } \\
\hline & $\begin{array}{l}\text { Patients to be } \\
\text { seen }\end{array}$ & All calls & $\begin{array}{l}\text { Adjusted odds ratio } \\
\text { (95\% confidence } \\
\text { intervals) }\end{array}$ & $\begin{array}{l}\text { Patients to be } \\
\text { seen at home }\end{array}$ & $\begin{array}{l}\text { All patients to } \\
\text { be seen }\end{array}$ & $\begin{array}{l}\text { Adjusted odds ratio } \\
\text { ( } 95 \% \text { confidence } \\
\text { intervals) }\end{array}$ \\
\hline \multicolumn{7}{|c|}{ Distance by road (km) } \\
\hline$<2$ & 2441 & 4072 & 1.00 & 626 & 2441 & 1.00 \\
\hline $2-<4$ & 7279 & 12574 & $0.96(0.88$ to 1.05$)$ & 1773 & 7279 & 0.9910 .83 to 1.19 \\
\hline $4-<6$ & 3173 & 5449 & $0.96(0.87$ to 1.05$)$ & 791 & 3173 & $1.08 / 0.89$ to 1.33 \\
\hline $6-<8$ & 1413 & 2467 & $0.82(0.73$ to 0.92$)$ & 334 & 1413 & $1.03 \quad 0.79$ to 1.34 \\
\hline $8-<10$ & 755 & 1324 & $0.78(0.67$ to 0.90$)$ & 211 & 755 & 1.34 (0.93 to 1.94 \\
\hline $10-<12$ & 812 & 1505 & $0.68(0.60$ to 0.78$)$ & 244 & 812 & $1.11 / 0.83$ to 1.48 \\
\hline $12-<14$ & 881 & 1678 & $0.70(0.62$ to 0.80$)$ & 248 & 881 & 1.38 (1.04 to 1.84 \\
\hline $14-<16$ & 444 & 977 & $0.52(0.45$ to 0.61$)$ & 90 & 444 & $1.24 \quad 0.82$ to 1.87 \\
\hline$\geqslant 16$ & 402 & 1002 & 0.38 (0.32 to 0.46$)$ & 96 & 402 & $1.04(0.69$ to 1.58 \\
\hline \multicolumn{7}{|c|}{ Socioeconomic deprivation category } \\
\hline 1 (least deprived) & 3588 & 6181 & 1.00 & 931 & 3588 & 1.00 \\
\hline 2 & 3510 & 6135 & 0.96 (0.89 to 1.03 ) & 847 & 3510 & $0.88 \quad 0.74$ to 1.05 \\
\hline 3 & 3524 & 6294 & $0.88(0.81$ to 0.95$)$ & 883 & 3524 & 1.20 (0.99 to 1.45 \\
\hline 4 & 3457 & 6210 & $0.81 \quad(0.75$ to 0.88$)$ & 909 & 3497 & 1.48 (1.23 to 1.78 \\
\hline 5 (most deprived) & 3481 & 6228 & $0.81 \quad(0.74$ to 0.88$)$ & 843 & 3481 & 1.98 (1.64 to 2.40 \\
\hline \multicolumn{7}{|l|}{ Gender } \\
\hline Male & 7874 & 13598 & 1.00 & 1871 & 7874 & 1.00 \\
\hline Female & 9726 & 17450 & 0.89 (0.85 to 0.94$)$ & 2542 & 9726 & 0.9510 .85 to 1.06 \\
\hline \multicolumn{7}{|l|}{ Rurality } \\
\hline Mainly urban & 15511 & 27058 & 1.00 & 3893 & 15511 & 1.00 \\
\hline Intermediate & 1345 & 2539 & 0.97 (0.88 to 1.07$)$ & 352 & 1385 & 0.8910 .70 to 1.13 \\
\hline Mainly rural & 704 & 1451 & $1.03(0.90$ to 1.18$)$ & 168 & 704 & $1.00 / 0.66$ to 1.50 \\
\hline \multicolumn{7}{|l|}{ Time of day } \\
\hline $1800-<2400$ & 8136 & 14716 & 1.00 & 1766 & 8136 & 1.00 \\
\hline $0000-<0800$ & 2207 & 4940 & $0.59(0.55$ to 0.63$)$ & 863 & 2207 & 1.64 (1.43 to 1.88 \\
\hline $0800-<1800$ & 7257 & 11392 & 1.20 (1.13 to 1.27$)$ & 1784 & 7257 & 1.42 (1.24 to 1.63 \\
\hline \multicolumn{7}{|l|}{ Day of week } \\
\hline Weekday & 7552 & 14703 & 1.00 & 2206 & 7552 & 1.00 \\
\hline Weekend & 10048 & 16345 & 1.33 (1.26 to 1.40$)$ & 2207 & 10048 & $0.48 \quad 0.42$ to 0.54 \\
\hline Total & 17600 & 31048 & & 4413 & 17600 & \\
\hline
\end{tabular}

Odds ratios are the odds for the decision to see the patient, relative to the baseline category obtained from logistic regression models that included distance, deprivation, age, sex, rurality, time of day, and day of week. $95 \%$ Confidence intervals were adjusted for multiple calls from the same person.

\section{Contributors}

JM designed the study and collected the data. RM and TP analysed the data. All authors contributed to writing and editing the paper. JM is the guarantor for the study.

\section{ACKNOWLEDGEMENTS}

This work uses data provided with the support of the ESRC and JISC, and census and boundary material, which are copyright of the Crown, the Post Office and the ED-LINE Consortium.

\section{Authors' affiliations}

J Munro, Medical Care Research Unit, University of Sheffield, Sheffield, UK

R Maheswaran, T Pearson, Public Health GIS Unit, University of Sheffield

Funding: none.
Competing interests: none declared.

Correspondence to: Dr J Munro, Medical Care Research Unit, University of Sheffield, Regent Court, 30 Regent Street, Sheffield S1 4DA, UK; j.f.munro@sheffield.ac.uk

Accepted for publication 3 April 2003

\section{REFERENCES}

1 Hallam L. Out of hours primary care. BM 1997;314:157-8.

2 Salisbury C, Trivella M, Bruster S. Demand for and supply of out-of-hours care from general practitioners in England and Scotland: observational study based on routinely collected data. BM 2000;320:618-21.

3 Morgan A, Shackley P, Pickin M, et al. Quantifying patient preferences for out-of-hours primary care. Journal of Health Services Research and Policy 2000;5:214-18

4 O'Reilly D, Stevenson M, McCay C, et al. General practice out-of-hours service, variations in use and equality in access to a doctor: a cross-sectional study. Br J Gen Pract 2001;51:625-9.

5 General Practitioners Committee. Your contract, your future. General practice contract and explanatory notes from the GPC. London: BMA, 2002. 